\title{
An epidemiological model of privational rickets and osteomalacia
}

\author{
BY MATTHEW G. DUNNIGAN AND JANET B. HENDERSON \\ University of Glasgow: Department of Human Nutrition, Glasgow Royal Infirmary, Glasgow G3I 2ER
}

Privational infantile rickets is now rare in the UK. Privational vitamin D deficiency remains common in the British Asian population, leading to neonatal, infantile and late rickets in childhood and osteomalacia (adult rickets) in Asian women (Dunnigan et al. 1962; Ford et al. 1972a, 1973; Holmes et al. 1973; Stamp et al. 1980). The prevalence of these manifestations of severe vitamin D deficiency in the Asian population has declined in the last 25 years. In the white population, privational osteomalacia is virtually confined to advanced old age (Gough et al. 1964; Anderson et al. 1966; Chalmers et al. 1967).

The advent of privational Asian rickets and osteomalacia to Britain in the 1960s offered an opportunity to re-examine the environmental factors which determine these diseases. The present paper describes the development of a risk-factor model for Asian privational rickets and osteomalacia based on examination of the relative roles of limited exposure to u.v. radiation (UVR) and dietary factors in their aetiology (Robertson et al. 1982; Henderson et al. 1987, 1990). The model provides an explanation for trends in the prevalence of privational rickets and osteomalacia in the UK in the present century and for the current prevalence of these diseases in the UK and in many underdeveloped Third World countries where they remain common (Dunnigan et al. 1982).

\section{RISK FACTORS FOR ASIAN RICKETS AND OSTEOMALACIA: EARLY OBSERVATIONS}

The discovery of late rickets and osteomalacia in the Glasgow Muslim community in 1961 (Dunnigan et al. 1962) was followed by a study of $7 \mathrm{~d}$ weighed dietary intakes in rachitic and normal Muslim schoolchildren and in a control group of white schoolchildren (Dunnigan \& Smith, 1965). Surprisingly, the dietary vitamin D intakes of rachitic Asian children, normal Asian children and Glasgow white children were similar. The higher fibre and phytate intakes of the Asian children were not considered aetiologically significant. Studies of daylight outdoor exposure showed no significant differences between the summer and non-summer exposures of rachitic and normal Muslim schoolchildren or between Muslim and white schoolchildren (Dunnigan, 1977). These patterns of daylight outdoor exposure did not conform to the Muslim 'purdah' stereotype, although sunbathing was unknown in the Asian community. It was also evident that many Glasgow white schoolchildren went out relatively little, even in fine weather, in a form of 'cultural purdah'. Similar patterns of apparently adequate daylight outdoor exposure were noted in Asian women with privational osteomalacia wearing Western dress in London (Compston, 1979). These observations did not support the hypothesis that Asian rickets and osteomalacia resulted from deficient exposure to UVR or from deficient dietary vitamin $\mathrm{D}$ intake relative to white women and children in whom privational rickets and osteomalacia were unknown outside infancy and old age.

The suggestion that Asian rickets in the UK might be related to the consumption of unleavened bread was supported by Mellanby's (1949) earlier identification of an anticalcifying factor in oatmeal, subsequently shown to be phytic acid, and by evidence of 'sunshine' rickets in Iranian village children consuming large quantities of unleavened bread (tanok) with abundant exposure to UVR (Rheinhold, 1972). Two uncontrolled trials 
demonstrated improvements in biochemical evidence of privational rickets in Asian children consuming chapatti-free diets (Ford et al. 1972b; Wills et al. 1972). Re-analysis of the $7 \mathrm{~d}$ weighed dietary survey carried out on Glasgow Muslim children showed significant univariate correlations between chapatti, phytate and fibre intakes and serum alkaline phosphatase (EC 3.1.3.1) concentrations (Dunnigan et al. 1975, 1976). Elevated concentrations of this enzyme reflect increased osteoblastic activity and showed a highly significant relationship with the presence and severity of radiological evidence of rickets in Asian children (Abdul Motaal et al. 1985). Multiple-regression analysis demonstrated that the univariate correlations were independent of other major dietary food class and nutrient variables and of the child's age and sex (Dunnigan et al. 1982; Robertson et al. 1982).

Support for the hypothesis that high intakes of high-extraction flour may be rachitogenic came from the unwitting experiment carried out in Ireland during the Second World War, when a decision to raise the extraction rate of the national flour from 70 to $100 \%$ resulted in a large rise in the number of cases of infantile rickets admitted to Dublin hospitals (Jessop, 1950; Robertson et al. 1981). Progressive reductions in the extraction rate of the flour led to comparable falls in the incidence of infantile rickets. This study suggested that high-extraction wheat cereal is potentially rachitogenic in young children.

Evidence that Asian rickets might be related to the consumption of high-extraction cereals was not generally accepted (Gupta et al. 1974; Dent \& Gupta, 1975). Many Third World populations adapt to low Ca intakes of less than $400 \mathrm{mg}$ daily, despite high fibre and phytate intakes, and show no evidence of privational rickets or osteomalacia. A considerable proportion of ingested phytate is also inactivated by phytase (EC 3.1.3.8.) in the alimentary tract. Evidence that serum 25-hydroxycholecalciferol concentrations were low in patients with Asian rickets and osteomalacia, which healed following the administration of vitamin D in supplements or chapatti flour, demonstrated that these conditions resulted from vitamin D deficiency and cast further doubt on the 'chapatti' hypothesis (Preece et al. 1975; Pietrek et al. 1976). The demonstration that over $90 \%$ of serum 25-hydroxycholecalciferol was endogenously synthesized following skin exposure to UVR, even in the high latitudes of the UK, confirmed the marginal role of dietary vitamin D (Poskitt et al. 1979). This evidence was reinforced by dose-response studies of vitamin $\mathrm{D}$-fortified foods and supplements which showed that an oral dose of not less than $10 \mu \mathrm{g}$ vitamin $\mathrm{D}$ was required to produce a significant rise in serum 25 -hydroxycholecalciferol concentrations (Dunnigan et al. 1982, 1985; Robertson et al. 1982). In summary, dietary factors appeared irrelevant to the aetiology of privational rickets and osteomalacia; the logical corollary implied that this could only result from inadequate exposure to UVR. As a consequence, the term 'nutritional' was replaced by 'privational' in relation to rickets and osteomalacia unrelated to underlying renal, hepatic or alimentary disease or to genetic factors.

\section{CASE-CONTROL STUDIES OF ASIAN RICKETS AND OSTEOMALACIA}

Further epidemiological studies of risk factors for privational rickets and osteomalacia seemed likely to yield maximum discrimination by comparing 'cases' (Dent, 1974) with normal controls. Between 1979 and 1985 records of $7 \mathrm{~d}$ weighed dietary intakes were completed by 188 Asian women and schoolchildren with and without privational rickets and osteomalacia living in Glasgow (Robertson et al. 1982; Henderson et al. 1987, 1990). Records of $7 \mathrm{~d}$ daylight outdoor exposure were completed in the autumn, winter and spring months (non-summer daylight outdoor exposure) during the weighed dietary surveys. These were supplemented by $7 \mathrm{~d}$ records of summer daylight outdoor exposure during the 
months of July and August; in the UK, effective endogenous vitamin D synthesis following UVR exposure occurs only between April and September. Cases of 'severe' rickets and osteomalacia discharged from Glasgow hospitals were compared with cases of 'mild' rickets and osteomalacia and with normal Asian women and children. The sources of the samples and operational definitions of 'severe' and 'mild' rickets and osteomalacia are detailed in the original publications (Henderson et al. 1987, 1990).

Data from the case-control studies were analysed by stepwise logistic analysis. Initial daylight outdoor exposure models compared non-summer and summer daylight outdoor exposure in rachitic and osteomalacic cases and controls. In the children's survey, a growth model then added age, sex and percentile height variables which measured the effects of growth velocity and gender on rachitic risk. Finally, in both surveys, food class and nutrient models incorporated all previous non-dietary variables with measurements of food class and nutrient intakes. The between-group discrimination provided by each logistic model was assessed by a model relative risk.

\section{Relationship between vegetarianism and privational rickets and osteomalacia}

The women's and children's dietary surveys and the initial dietary survey of Muslim schoolchildren carried out in 1964 (Dunnigan \& Smith, 1965) showed a strong association between vegetarianism and the prevalence and severity of privational rickets and osteomalacia (Table 1). Previous studies had shown a strong association between vegetarianism and privational rickets and osteomalacia in a wide range of populations (Chick et al. 1923; Hess, 1930; Dent \& Gupta, 1975; Brooke et al. 1980). Interpretation of this association is handicapped by confounding variables of poverty, overcrowding and religious habit which may limit exposure to UVR. It is also impossible to ascertain whether the risk of rickets and osteomalacia associated with vegetarianism derives from lack of animal and dairy foods or from an excess of vegetarian foods containing substances such as phytic acid and fibre which may reduce $\mathrm{Ca}$ absorption.

\section{Case-control study of Asian rickets}

The summer daylight outdoor exposures of all rachitic children were significantly lower than those of normal children (rachitic median $91 \mathrm{~min} / \mathrm{d}$; normal median $158 \mathrm{~min} / \mathrm{d}$;

Table 1. Prevalence of lacto-vegetarianism in 117 rachitic and normal Asian children and in 104 osteomalacic and normal Asian women

\begin{tabular}{llcr}
\hline \hline & $n$ & No. of vegetarians & Percentage vegetarian \\
\hline Children & & & 70 \\
Rachitic deformity & 10 & 7 & 24 \\
'Severe' rickets & 29 & 7 & 0 \\
'Mild' rickets & 25 & 0 & 4 \\
Normal & 53 & 2 & 100 \\
Women & & & 40 \\
'Severe' osteomalacia & 12 & 12 & 8 \\
'Mild' osteomalacia & 15 & 6 & 6 \\
Normal & 77 & 6 & \\
\hline
\end{tabular}


$P<0.05$ ); logistic model between-group discrimination was not significant (model relative risk 2.0; not significant). The non-summer daylight outdoor exposures of all rachitic children were also significantly lower than those of normal children (rachitic median $64 \mathrm{~min} / \mathrm{d}$; normal median $84 \mathrm{~min} / \mathrm{d} ; P<0.01$ ); logistic model between-group discrimination was relatively poor (model relative risk $2.6 ; P=0.02$ ). The non-summer daylight outdoor exposures of Asian children with 'severe' rickets were significantly lower than those of normal children (rachitic median $57 \mathrm{~min} / \mathrm{d}$; normal median $84 \mathrm{~min} / \mathrm{d} ; P<0.05$ ); logistic model between-group discrimination exceeded that for comparisons between all rachitic and normal children (model relative risk $4.7 ; P=0.02$ ). The growth model showed further improvement in between-group discrimination, reflecting the effect of the pubertal growth spurt on rachitic risk (model relative risk $8.4 ; P=0.002$ ). The greatest discrimination was provided by the food class (model relative risk $17.9 ; P<0.001$ ) and nutrient models (model relative risk $15.1 ; P<0.001$ ). In decreasing order of significance, discrimination provided by the food-class model reflected significantly higher intakes of chapatti, lower intakes of meat (in the present review the term 'meat' includes intakes of beef, lamb, poultry and meat products), and lower daylight outdoor exposures in children with 'severe' rickets compared with normal children. Similarly, in decreasing order of significance, discrimination provided by the nutrient model reflected significantly lower intakes of $P$, higher intakes of fibre and lower daylight outdoor exposures in children with 'severe' rickets compared with normal children.

Children with 'mild' rickets had significantly lower non-summer daylight outdoor exposures than normal children (rachitic median $67 \mathrm{~min} / \mathrm{d}$; normal median $84 \mathrm{~min} / \mathrm{d}$; $P<0.05$ ); logistic model between-group discrimination was relatively poor (model relative risk $3.0 ; P=0.04$ ). Discrimination significantly increased in the growth model (model relative risk 8.6; $P<0.001$ ) and was greatest in the food class (model relative risk 12.7; $P<0.001$ ) and nutrient models (model relative risk 26.1;P<0.001). In decreasing order of significance discrimination provided by the food-class model reflected significantly lower intakes of meat, lower daylight exposures and increased growth velocities in children with 'mild' rickets compared with normal children. Similarly, in decreasing order of significance, discrimination provided by the nutrient model reflected significantly lower protein intakes, higher $\mathbf{P}$ intakes, lower daylight outdoor exposures and increased growth velocities in children with 'mild' rickets compared with normal children.

This case-control study demonstrated that dietary factors determine the occurrence and severity of late rickets in Asian schoolchildren in a setting of restricted UVR exposure. The chapatti and fibre risk factors dominated the 'severe' rickets food-class model containing predominantly Muslim children, and were absent in the 'mild' rickets food-class model in which most children were Sikh and Hindu, adhering to a lacto-vegetarian dietary pattern.

\section{Case-control study of Asian osteomalacia}

Summer daylight outdoor exposures of Asian women with osteomalacia were not significantly different from those of normal women (osteomalacic median $51 \mathrm{~min} / \mathrm{d}$; normal median $69 \mathrm{~min} / \mathrm{d}$ ); logistic model between-group discrimination was not significant (model relative risk 1.7). The non-summer daylight outdoor exposures of osteomalacic women were significantly lower than those of normal women (osteomalacic median $25 \mathrm{~min} / \mathrm{d}$; normal median $45 \mathrm{~min} / \mathrm{d} ; P=0.04$ ); logistic model between-group discrimination was relatively poor (model relative risk $3 \cdot 0 ; P=0.04$ ). 
Daylight outdoor exposure variables were eliminated from the final food-class and nutrient models as they made no significant independent contributions to osteomalacic risk. The food-class model showed highly significant discrimination between osteomalacic and normal women (model relative risk 13.4; $P<0.001$ ). In decreasing order of significance, discrimination reflected the significantly increased prevalence of lacto-vegetarianism, ovolacto-vegetarianism and high vegetable intakes in osteomalacic women compared with normal women. The nutrient model provided relatively poor between-group discrimination (model relative risk $3.9 ; P=0.01$ ). In decreasing order of significance, discrimination reflected significantly higher intakes of fibre, increased age and lower vitamin D intakes in osteomalacic women compared with normal Asian women. The small difference in median daily vitamin intake between osteomalacic and normal women $(0.4 \mu \mathrm{g})$ is biologically nonsignificant. All twelve patients with 'severe' osteomalacia characterized by severe symptoms of pain with myopathy, abnormal biochemistry and positive radiology (Looser's zones or pseudo fractures) were strict lacto-vegetarians. Six of fifteen $(40 \%)$ patients with 'mild' (X-ray negative) osteomalacia and only six of seventy-seven $(8 \%)$ normal women were lacto-vegetarian (Table 1).

This case-control study demonstrated that the prevalence of osteomalacia in Asian women was dominated by the categorical risk factor of lacto-vegetarianism (absent meat, fish and egg intakes). Dietary intakes of chapatti, phytate and fibre provided non-significant or poor between-group discrimination. $\mathrm{Ca}$ intakes were higher in lacto-vegetarian Asian women with osteomalacia than in normal women.

\section{The distribution of risk factors for Asian rickets and osteomalacia by religion}

The traditional diets of the Muslim, Sikh and Hindu populations of the UK show distinct differences. The Muslim diet contains meat (chicken, lamb and beef) in relatively low amounts compared with the omnivore white population; high-extraction wheat cereal is consumed in relatively large amounts, mainly as chapatti. The Sikh and Hindu populations consume a lacto-vegetarian diet in which meat intakes are low or zero; $\mathrm{Ca}$ and milk intakes are relatively higher and high-extraction cereal intakes relatively lower than those in the Muslim population. Intakes of pulses are relatively higher in the Sikh and Hindu populations than in the Muslim population, acting as a meat substitute.

The distribution of univariate risk factors for Asian rickets and osteomalacia by religious affiliation reflects these differences. Muslim children with 'severe' rickets consumed significantly higher amounts of chapatti, fibre and phytate and lower amounts of milk than normal Muslim children; meat intakes were not significantly different (Table 2). Sikh and Hindu children with 'severe' rickets consumed significantly lower amounts of meat, eggs, fish and vitamin D and significantly higher amounts of pulses than normal Sikh and Hindu children; fibre and phytate intakes were not significantly different (Table 3). The small difference in median daily vitamin $D$ intake $(0.52 \mu \mathrm{g})$ between children with 'severe' rickets and normal children is biologically non-significant.

Of twelve lacto-vegetarian Asian women with severe osteomalacia only one was Muslim. This woman had been a strict lacto-vegetarian since childhood. Sikh and Hindu women with 'severe' osteomalacia consumed significantly lower amounts of meat and vitamin $D$, and significantly higher amounts of pulses than normal Sikh and Hindu women; fibre and phytate intakes were not significantly different (Table 4). The small difference in median daily vitamin D intake $(0.8 \mu \mathrm{g})$ between women with 'severe' osteomalacia and normal women appears biologically non-significant. 
Table 2. Significant univariate differences in daily food and nutrient intakes between rachitic and normal Muslim children ( $7 d$ weighed intakes)

(Values are medians and ranges)

\begin{tabular}{|c|c|c|c|c|c|c|c|c|}
\hline \multirow[b]{2}{*}{ Variable } & \multicolumn{2}{|c|}{$\begin{array}{l}\text { 'Severe' rickets } \\
(n \text { 10) }\end{array}$} & \multirow{2}{*}{$\begin{array}{c}\text { Statistical } \\
\text { significance of } \\
\text { difference from } \\
\text { normal*: } P\end{array}$} & \multicolumn{2}{|c|}{$\begin{array}{l}\text { All rickets } \dagger \\
\quad(n \text { 14) }\end{array}$} & \multirow{2}{*}{$\begin{array}{c}\text { Statistical } \\
\text { significance of } \\
\text { difference from } \\
\text { normal: } \uparrow P\end{array}$} & \multicolumn{2}{|c|}{$\begin{array}{c}\text { Normal } \\
(n 15)\end{array}$} \\
\hline & Median & Range & & Median & Range & & Median & Range \\
\hline Age (years) & 14 & $10-16$ & 0.02 & 13 & $9-16$ & 0.08 & 11 & $7-17$ \\
\hline Chapatti $(\mathrm{g} / \mathrm{d})$ & 156 & $87-681$ & 0.004 & 141 & $66-681$ & 0.005 & 75 & $36-288$ \\
\hline Phytate $(\mathrm{mg} / \mathrm{d})$ & 144 & $97-458$ & 0.008 & 144 & $93-458$ & 0.007 & 98 & $60-224$ \\
\hline Fibre $(g / d)$ & 25 & $17-56$ & 0.02 & 25 & $17-56$ & 0.02 & 20 & $16-33$ \\
\hline Milk (ml/d) & 127 & $17-417$ & 0.04 & 133 & $17-514$ & NS & 286 & $81-625$ \\
\hline
\end{tabular}

* Mann-Whitney U test.

†'Severe' and 'mild' rickets.

Table 3. Significant univariate differences in daily food and nutrient intakes between rachitic and normal Sikh and Hindu children ( $7 d$ weighed intakes)

(Values are medians and ranges)

\begin{tabular}{|c|c|c|c|c|c|c|c|c|}
\hline \multirow[b]{2}{*}{ Variable } & \multicolumn{2}{|c|}{$\begin{array}{l}\text { 'Severe' rickets } \\
(n \text { 6) }\end{array}$} & \multirow{2}{*}{$\begin{array}{c}\text { Statistical } \\
\text { significance of } \\
\text { difference from } \\
\text { normal*: } P\end{array}$} & \multicolumn{2}{|c|}{$\begin{array}{l}\text { All rickets } \dagger \\
\text { (n 29) }\end{array}$} & \multirow{2}{*}{$\begin{array}{c}\text { Statistical } \\
\text { significance of } \\
\text { difference from } \\
\text { normal*: } P\end{array}$} & \multicolumn{2}{|c|}{$\begin{array}{c}\text { Normal } \\
(n \text { 26) }\end{array}$} \\
\hline & Median & Range & & Median & Range & & Median & Range \\
\hline Age (years) & 13 & $8-14$ & NS & 13 & $7-17$ & NS & 11 & $7-18$ \\
\hline Meat $(\mathrm{g} / \mathrm{d})$ & 16 & $0-34$ & 0.005 & 43 & $0-301$ & NS & 47 & $0-191$ \\
\hline Pulses (g/d) & 106 & $81-162$ & 0.01 & 97 & $0-170$ & 0.02 & 54 & $0-154$ \\
\hline Eggs $(\mathrm{g} / \mathrm{d})$ & 4 & $0-17$ & 0.03 & 16 & $0-94$ & NS & 23 & $0-67$ \\
\hline Fish $(\mathrm{g} / \mathrm{d})$ & 0 & 0 & 0.03 & 11 & $0-98$ & NS & 13 & $0-45$ \\
\hline Vitamin D $(\mu \mathrm{g} / \mathrm{d})$ & 0.45 & $0.2-0.7$ & 0.003 & 0.91 & $0.2-4.2$ & NS & 0.97 & $0.1-2.7$ \\
\hline Protein $(\mathrm{g} / \mathrm{d})$ & 45 & $26-64$ & 0.02 & 61 & $26-133$ & NS & 60 & $35-109$ \\
\hline
\end{tabular}

* Mann-Whitney U test.

†'Severe' and 'mild' rickets.

Table 4. Significant univariate differences in daily food and nutrient intakes between osteomalacic and normal Sikh and Hindu women* ( $7 d$ weighed intakes)

(Values are medians and ranges)

\begin{tabular}{|c|c|c|c|c|c|c|c|c|}
\hline \multirow[b]{2}{*}{ Variable } & \multicolumn{2}{|c|}{$\begin{array}{c}\text { 'Severe' osteomalacia } \\
(n 6)\end{array}$} & \multirow{2}{*}{$\begin{array}{c}\text { Statistical } \\
\text { significance of } \\
\text { difference from } \\
\text { normal } \dagger: P\end{array}$} & \multicolumn{2}{|c|}{$\begin{array}{l}\text { All osteomalacia } \ddagger \\
(n \text { 14) }\end{array}$} & \multirow{2}{*}{$\begin{array}{c}\text { Statistical } \\
\text { significance of } \\
\text { difference from } \\
\text { normal }+: P\end{array}$} & \multicolumn{2}{|c|}{$\begin{array}{l}\text { Normal } \\
(n 21)\end{array}$} \\
\hline & Median & Range & & Median & Range & & Median & Range \\
\hline Age (years) & 43 & $21-66$ & NS & 41 & $21-66$ & NS & 36 & $21-54$ \\
\hline Meat $(g / d)$ & 0 & 0 & 0.007 & 0 & $0-78$ & 0.008 & 34 & $0-149$ \\
\hline Pulses $(\mathrm{g} / \mathrm{d})$ & 163 & $119-264$ & 0.003 & 145 & $40-321$ & 0.002 & 76 & $0-250$ \\
\hline Vitamin $\mathrm{D}(\mu \mathrm{g} / \mathrm{d})$ & 0.9 & $0.4-1.2$ & 0.06 & 1.0 & $0.3-2 \cdot 2$ & 0.07 & 1.7 & $0.3-3.7$ \\
\hline
\end{tabular}

* There were no significant food and nutrient differences between five Muslim women with mild osteomalacia and fiftytwo normal women.

$\dagger$ Mann-Whitney U test.

\$ 'Severe' and 'mild' osteomalacia. 
Only five of fifty-seven Muslim women in the women's study had mild osteomalacia. There were no significant food-class or nutrient differences between cases and controls. As noted previously, one Muslim woman with 'severe' osteomalacia was a strict lactovegetarian.

\section{Potential calcium binding by dietary phytate and fibre in Asian women and children}

Maximal potential $\mathrm{Ca}$ binding by dietary fibre and phytate was assessed for each participant in the women's and children's dietary surveys (James et al. 1978). The calculation makes no allowance for enzymic degradation of phytic acid by alimentary phytase, or for the release of $\mathrm{Ca}$ bound to dietary fibre in the large bowel following the bacterial degradation of uronic acid (James et al. 1978). The analysis showed a significant fall in unbound $\mathrm{Ca}$ intakes in Muslim children with 'severe' rickets compared with normal children, and a non-significant fall in Muslim children with 'mild' rickets compared with normal Muslim children (Table 5). Unbound $\mathrm{Ca}$ intakes were not significantly different between Sikh and Hindu children with 'mild' or 'severe' rickets and normal Sikh and Hindu children, or between Sikh, Hindu and Muslim women with 'mild' or 'severe' osteomalacia and their normal counterparts. These findings support the evidence of the women's and children's food-class and nutrient logistic models and of the analysis of univariate risk factors for Asian rickets and osteomalacia by religious affiliation (see $p$. 943). High-extraction wheat cereal appears potentially rachitogenic in Muslim Asian

Table 5. Total and unbound $\dagger$ calcium intakes after maximum potential binding by dietary phytate and fibre in Asian children and women with privational rickets and osteomalacia (Values are medians and ranges)

\begin{tabular}{|c|c|c|c|c|c|}
\hline & \multirow[b]{2}{*}{$n$} & \multicolumn{2}{|c|}{ Total Ca (mg/d) } & \multicolumn{2}{|c|}{ Unbound $\mathrm{Ca}$ (mg/d) } \\
\hline & & Median & Range & Median & Range \\
\hline \multicolumn{6}{|l|}{ Muslim children } \\
\hline 'Severe' rickets & 10 & 669 & $335-1097$ & $115^{*}$ & $-203-678$ \\
\hline 'Mild' rickets & 14 & 946 & $392-1018$ & 470 & $108-630$ \\
\hline Normal & 15 & 803 & $530-1433$ & 518 & $240-1135$ \\
\hline \multicolumn{6}{|l|}{ Sikh and Hindu children } \\
\hline 'Severe' rickets & 6 & 953 & $277-1110$ & 467 & $32-687$ \\
\hline 'Mild' rickets & 23 & 1060 & $321-2161$ & 731 & $-2-1376$ \\
\hline Normal & 26 & 934 & $291-1506$ & 612 & $32-1030$ \\
\hline \multicolumn{6}{|l|}{ Muslim women } \\
\hline 'Severe' osteomalacia & 1 & & - & - & \\
\hline 'Mild' osteomalacia & 5 & 833 & $184-1090$ & 368 & $-28-808$ \\
\hline Normal & 52 & 709 & $288-1228$ & 292 & $-70-826$ \\
\hline \multicolumn{6}{|l|}{ Sikh and Hindu women } \\
\hline 'Severe' osteomalacia & 6 & 1048 & $872-1272$ & 498 & $334-849$ \\
\hline 'Mild' osteomalacia & 8 & 887 & $628-1580$ & 395 & $21-1322$ \\
\hline Normal & 21 & 803 & $453-1582$ & 509 & $106-1034$ \\
\hline
\end{tabular}

Median value for normal unbound Ca for Muslim children with 'severe' rickets was significantly different from that for normal children (Mann-Whitney $\mathrm{U}$ test): ${ }^{*} P=0.002$. There were no other significant between-group differences.

†Unbound Ca intake $(\mathrm{mg} / \mathrm{d})=\mathrm{Ca}$ intake $(\mathrm{mg} / \mathrm{d})-($ phytate intake $(\mathrm{mg} / \mathrm{d}) \times 1.27)-($ fibre intake $(\mathrm{g} / \mathrm{d}) \times 8.8)(\mathrm{James}$ et al. 1978). 
children with 'severe' rickets by reducing available unbound $\mathrm{Ca}$ in the presence of low $\mathrm{Ca}$ intakes; the extent of binding in vivo is uncertain. Ca binding by dietary phytate and fibre appears a non-significant or weak risk factor for rickets or osteomalacia in lacto-vegetarian Sikh and Hindu women and children with high $\mathrm{Ca}$ intakes, and in non-vegetarian Muslim women who consume small quantities of meat and meat products.

\section{AETIOLOGICAL MECHANISMS FOR ASIAN RICKETS AND OSTEOMALACIA}

\section{Calcium binding by high-extraction cereals}

Preliminary attempts to link $\mathrm{Ca}$ binding by dietary fibre and phytate to the vitamin $\mathrm{D}$ metabolic pathway centred on the interruption of an entero-hepatic circulation of vitamin $D$ metabolites by components of dietary cereal (Arnaud et al. 1975; Rheinhold, 1976). More recent evidence suggests that this circulation is functionally unimportant (Clements et al. 1984). In a series of elegant experiments in the rat, Clements et al. (1987) showed that a low-Ca diet resulted in secondary hyperparathyroidism with a rise in serum 1,25dihydroxycholecalciferol. The rise in serum 1,25-dihydroxycholecalciferol induced a fall in serum 25-hydroxycholecalciferol, with increased turnover and inactivation of the latter metabolite from a limited substrate.

This mechanism links low Ca intakes due to dietary deficiency, Ca malabsorption or $\mathrm{Ca}$ binding with vitamin $\mathrm{D}$ deficiency where endogenous synthesis of serum 25hydroxycholecalciferol is restricted by limited exposure to UVR. It explains both the rachitogenic role of high-extraction cereal in Muslim Asian children and the rise of infantile rickets in Ireland following the exposure of young children to intakes of $100 \%$ extraction flour noted previously (Clements, 1989; Fraser, 1995). It cannot explain the occurrence of privational rickets and osteomalacia in lacto-vegetarian Sikh and Hindu women and children in whom high $\mathrm{Ca}$ intakes more than compensate for $\mathrm{Ca}$ binding by dietary fibre and phytate. This reservation also applies to the aetiology of infantile rickets; this is usually associated with prolonged weaning with high intakes of milk, $\mathrm{Ca}$ and refined and complex carbohydrate in the first and second years of life (Corry Mann, 1922).

\section{Low intakes of animal foods (meat, fish and eggs)}

The major independent risk factor for privational rickets and osteomalacia in Sikh and Hindu women and children is a lacto-vegetarian diet containing little or no meat, fish or eggs and high intakes of $\mathrm{Ca}$ and milk. Low or absent meat intakes are the dominant component of this risk factor. The reasons for the highly protective action of meat against privational rickets and osteomalacia remain uncertain. Mellanby (1920) identified meat as strongly anti-rachitic in his initial puppy rickets model. He further commented that the protective action of meat appeared independent of its content of his anti-rachitic factor, subsequently identified as vitamin D (Mellanby, 1921). Recent analyses have shown that vitamin $\mathrm{D}$ and 25-hydroxycholecalciferol are present in meat in low concentrations, equivalent to an average of 7 (range 1-19) $\mu \mathrm{g}$ vitamin D/ $\mathrm{kg}$ beef, veal, lamb, pork, chicken and turkey (Chan et al. 1995). This would add only $0.3-0.4 \mu \mathrm{g}$ vitamin D daily to the median meat intakes of the normal Asian women $(49 \mathrm{~g} / \mathrm{d})$ and children $(61 \mathrm{~g} / \mathrm{d})$ who participated in the surveys reported previously. This cannot account for the highly protective action of meat against rickets and osteomalacia identified in the food-class logistic models discussed previously (Henderson et al. 1987, 1990). The average vitamin D content of $100 \mathrm{~g}$ meat $(0.7 \mu \mathrm{g})$ is equivalent to the vitamin $\mathrm{D}$ content of $570 \mathrm{ml}$ (about 1 pint) cows' milk (Reeve et al. 1982). Infantile and lacto-vegetarian rickets and 
osteomalacia are commonly associated with milk intakes of this magnitude. At average UK meat consumption levels of about $150 \mathrm{~g} / \mathrm{d}$, the new analyses would add about $1.0 \mu \mathrm{g}$ vitamin D daily to the British diet. Dose-response studies of vitamin D in foods and supplements also indicate that $1.0 \mu \mathrm{g}$ vitamin D would not produce a significant rise in serum 25-hydroxycholecalciferol concentrations (Dunnigan et al. 1982, 1985; Robertson et al. 1982).

Dietary protein has a significant effect on the oxidative transformation of drugs in man via an effect on the cytochrome $\mathrm{P}_{450}$-dependent mixed function oxidase system in the liver (Alvarez et al. 1976; Dollery et al. 1977). Components of meat protein (and possibly of egg and fish protein) may selectively increase the oxidation of cholecalciferol to 25hydroxycholecalciferol and, thus, ensure the more efficient utilization of endogenouslyderived cholecalciferol when UVR exposure is limited. Meat also enhances the bioavailability of vegetable-derived $\mathrm{Fe}$ and possibly of other trace elements such as $\mathrm{Zn}$, $\mathrm{Cu}$ and Se (Shah, 1981; Snedeker \& Greger, 1983). The effect on the bioavailability of dietary $\mathrm{Ca}$ and/or vitamin $\mathrm{D}$ of adding meat and animal fat to a vegetarian diet does not appear to have been examined. Experimental validation of these hypothetical links between meat intakes and vitamin $\mathrm{D}$ and $\mathrm{Ca}$ metabolism is now required.

\section{Serum 25-hydroxycholecalciferol concentrations in East African Asians in London}

Indirect evidence that high meat intakes may increase serum 25-hydroxycholecalciferol concentrations in Asian subjects to 'white' levels was provided by a study of the $7 \mathrm{~d}$ weighed dietary intakes and daylight outdoor exposures of eighty-one East African Asians (Hunt et al. 1976). In a study of five religious groups (Hindu, Sikh, Muslim, Ismaili and Goan Roman Catholic), there was a progressive rise in mean serum 25-hydroxycholecalciferol concentrations from low levels in the lacto-vegetarian Hindu sample to 'white' concentrations in the Roman Catholic Goan sample who consumed a 'Western-type diet'.

There were no significant differences in mean daylight outdoor exposure among the five religious groups. Vitamin D dose-response studies (Dunnigan et al. 1982, 1985; Robertson et al. 1982) indicate that the small differences in mean dietary vitamin D intakes (Hindu mean 0.68 (SD 0.8) $\mu \mathrm{g}$; Goan mean 1.90 (SD 1.28) $\mu \mathrm{g}$ ) between the Hindu and Goan samples could not account for the gradient in mean serum 25-hydroxycholecalciferol concentrations across the religious groups (Hindu mean 9.8 (SD 4.8) nmol/1; Goan mean 31.8 (SD 9.8) nmol/l). The higher $\mathrm{Ca}$ intakes of the lacto-vegetarian Hindu diet compensated for potentially-increased $\mathrm{Ca}$ binding by the higher fibre and phytate intakes of the Hindu sample.

Hunt et al. (1976) did not publish the meat and fish intakes of the participants in their study. Enquiry by the authors of seven London and Glasgow Goan families (sixteen adults and four children) in 1995 indicated that they consumed an omnivore diet with high intakes of meat and fish (except for one vegetarian subject). Records of 1-week household food purchases for the seven families indicated the availability of about $240 \mathrm{~g}$ meat, poultry, fish, and meat and fish products for daily consumption by each omnivore family member. While these estimates measured the estimated weight of purchased foods before preparation, cooking or consumption, they suggest that the British Goan population consumes meat and fish in similar quantities to the white population. The Goan population is genetically similar to other Asian religious groups in the UK and has the darkest skin of the five religious groups participating in the Hunt et al. (1976) study. 


\section{A UVR-DIET MODEL OF PRIVATIONAL RICKETS AND OSTEOMALACIA}

Where UVR is limited by latitude and urbanization, the prevalence of privational rickets and osteomalacia is determined by dietary factors. Limited UVR is necessary but insufficient to induce 'cases' of privational rickets or osteomalacia unless the diet deviates from the Western omnivore pattern. This diet is characterized by high intakes of meat, fish and eggs, and low intakes of high-extraction cereals. The Western omnivore diet provides complete protection from privational rickets and osteomalacia from infancy to old age at the low levels of dietary vitamin $D$ intake which characterize the largely unfortified British diet and at the levels of casual exposure to UVR experienced in the high latitudes of the UK. An omnivore Western diet will not prevent hypovitaminosis D at very low or zero UVR exposure levels; by inducing mild secondary hyperparathyroidism this may contribute to the risk of type two osteoporosis in old age.

As the dietary pattern moves from omnivore to vegetarian, rachitic and osteomalacic risk rise synergistically with falling exposure to UVR (Fig. 1). UVR exposure levels associated with Asian rickets and osteomalacia in the UK are similar to the casual daylight exposure levels of a substantial proportion of the urban white population. Dietary risk factors for privational rickets and osteomalacia are independent of the low vitamin $D$ content of most foods and appear to result from interactions between constituents of animal foods (predominantly meat and meat products) and the intermediary metabolism of endogenously-synthesized vitamin $\mathrm{D}$. In children, $\mathrm{Ca}$ binding by components of highextraction cereals provides an additional potential risk factor, probably through the mechanism demonstrated by Clements et al. (1987) and Clements (1989). The absorption of $\mathrm{Ca}$ from the colon after its release from the inactivated uronic acid component of dietary fibre is vitamin D dependent. At the low levels of sunlight exposure found in the UK, Ca binding by dietary fibre may be a more significant risk factor for privational rickets than in sub-tropical and tropical climates (James et al. 1978). Low dietary Ca intakes may also contribute to the risk of vitamin $\mathrm{D}$ deficiency associated with vegan diets or severe

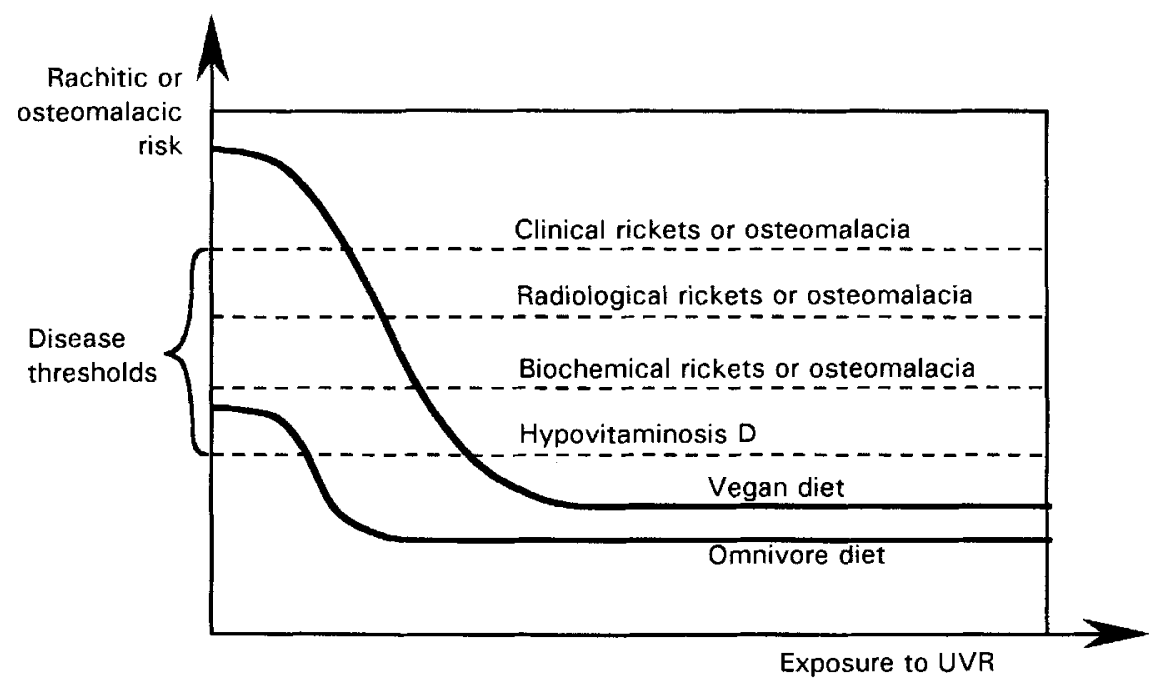

Fig. 1. Schematic representation of the relationships between u.v. radiation (UVR) exposure, dietary pattern (veganomnivore) and rachitic or osteomalacic risk. (From Dunnigan, 1992.) 
malnutrition (Fraser, 1995). Ca binding by dietary fibre and phytate is not a risk factor for privational rickets and osteomalacia in the presence of a high-Ca lacto-vegetarian diet.

'Sunshine' rickets due to very low $\mathrm{Ca}$ intakes has been described in tropical and subtropical climates in association with poor vegan diets. South African and Nigerian patients with low-Ca rickets had normal serum 25-hydroxycholecalciferol concentrations and their rickets was healed by Ca supplementation (Pettifor et al. 1978; Okonofua et al. 1991). In these situations, the effect of a low-Ca diet in lowering serum 25-hydroxycholecalciferol concentrations is presumably masked by intense UVR exposure.

In summary, the UVR-diet model outlined explains the paradox that dietary factors determine the prevalence and severity of privational rickets and osteomalacia, although most vitamin $\mathrm{D}$ is derived by endogenous synthesis from inactive skin precursors following exposure to UVR.

\section{TRENDS IN THE PREVALENCE OF ASIAN RICKETS AND OSTEOMALACIA}

Examination of the case records of all Asian patients discharged from Glasgow hospitals with a diagnosis of rickets or osteomalacia between 1968 and 1994 shows a progressive decline in the prevalence of these diseases (Fig. 2). Evidence from the Glasgow Asian community suggests that most Asian children have adopted a mixed Asian and Western diet with the consumption of more meat and fish at home, at school and from fast-food outlets. This trend has been accompanied by a significant rise in the incidence of appendicitis in the Glasgow Asian community, particularly in Asian boys who have adapted more rapidly to a Western omnivore diet than Asian girls (Matheson et al. 1988). The provision of free vitamin D supplements in 1979 in an effort to reduce the prevalence of Asian rickets in the city is not responsible for this trend (Dunnigan et al. 1985). Supplement uptake declined rapidly within a few years of the onset of the campaign and vitamin D supplements are now rarely consumed by Asian schoolchildren and women (Henderson et al. 1989). Asian women who follow traditional lacto-vegetarian diets in Sikh and Hindu communities in the UK remain at significant risk of privational osteomalacia (Dandona et al. 1985). The prevalence of Asian rickets in the UK has followed the declining Glasgow trend.

\section{TRENDS IN THE PREVALENCE OF INFANTILE RICKETS IN THE UNITED KINGDOM}

Fig. 3 shows discharges with privational infantile rickets from the Royal Hospital for Sick Children in Glasgow between 1948 and 1967 (Arneil et al. 1965; Richards et al. 1968) and from all Glasgow hospitals between 1968 and 1994. All case records of patients discharged during the latter period were examined. The fall in discharges resulting from the introduction of vitamin D-fortified welfare foods and supplements during the Second World War was followed by a sharp rise in the 1960s. This followed a reduction in the vitamin $\mathrm{D}$ content of welfare foods in response to the discovery of infantile hypercalcaemia (Richards et al. 1968). Following a 1965 peak, discharges with a diagnosis of infantile rickets from all Glasgow hospitals fell; between 1976 and 1988 there were only six discharges with this diagnosis and there were none between 1989 and 1994 . The virtual disappearance of infantile rickets from the infant and toddler population of Glasgow since 1970 is unrelated to major changes in housing in the city. Measurements of UVR falling on Glasgow obtained from the Glasgow Weather Centre show no significant changes over this period. Daily doses of vitamin D supplements dispensed from Greater Glasgow Health 

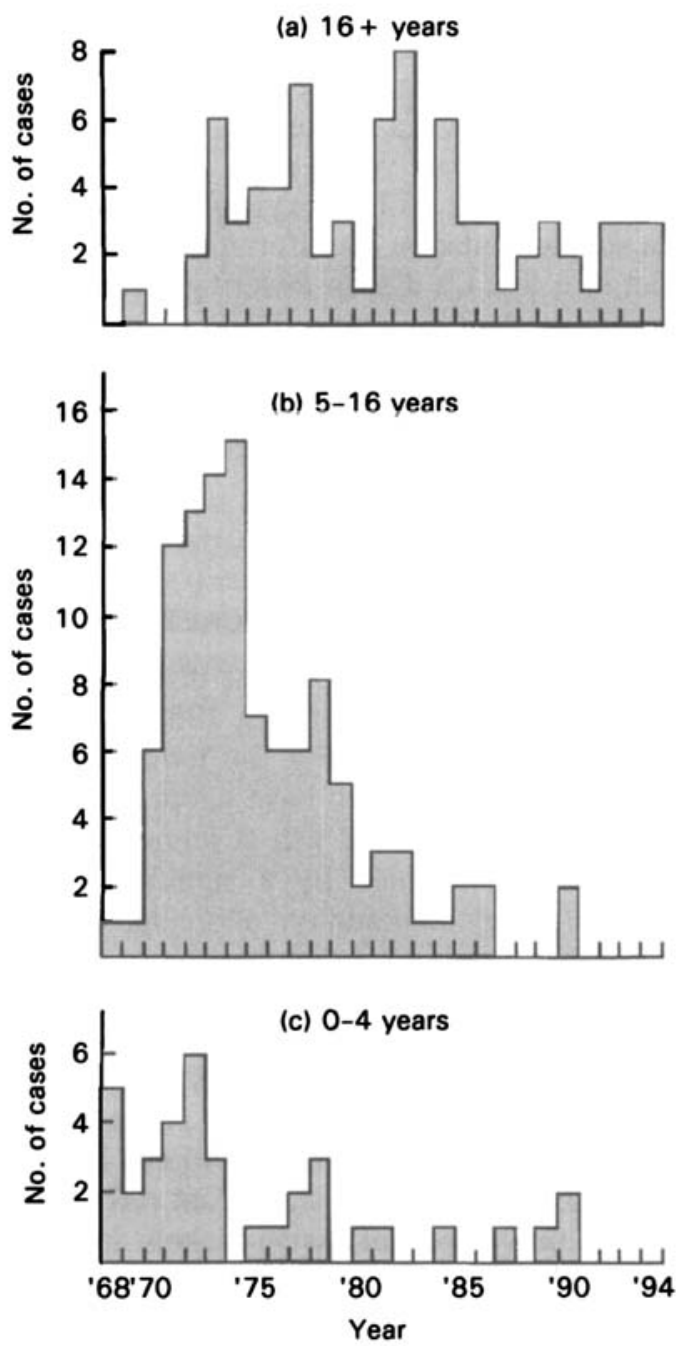

Fig. 2. Discharges of Asian children with privational infantile and late rickets and of Asian women with privational osteomalacia from all Glasgow hospitals between 1968 and 1994.

Board's central pharmacy fell from $141007.0 \mu \mathrm{g}$ doses daily in 1980 to 5000 doses daily in 1994 for an estimated preschool (0-5 years) population of 59800 in 1991.

The UVR-diet model outlined previously suggests that the decline and virtual disappearance of infantile rickets from Glasgow and the UK reflects a progressive change in infant and toddler feeding patterns from lacto-vegetarian to omnivore during the past century. Corry Mann (1922) provided detailed documentation of the dietary intakes of rachitic infants and toddlers in London in the early years of the present century. Late weaning at 9 months or later from breast or cows' milk as the only source of nutrition was followed by supplementation with sugar, bread and potatoes. The diets of rachitic children contained little or no meat, eggs, fish or animal fats (suet, dripping, bacon fat or butter). Corry Mann (1922) noted that rachitic toddlers in London appeared to have adequate casual levels of urban outdoor exposure, living in low-rise housing with gardens and 


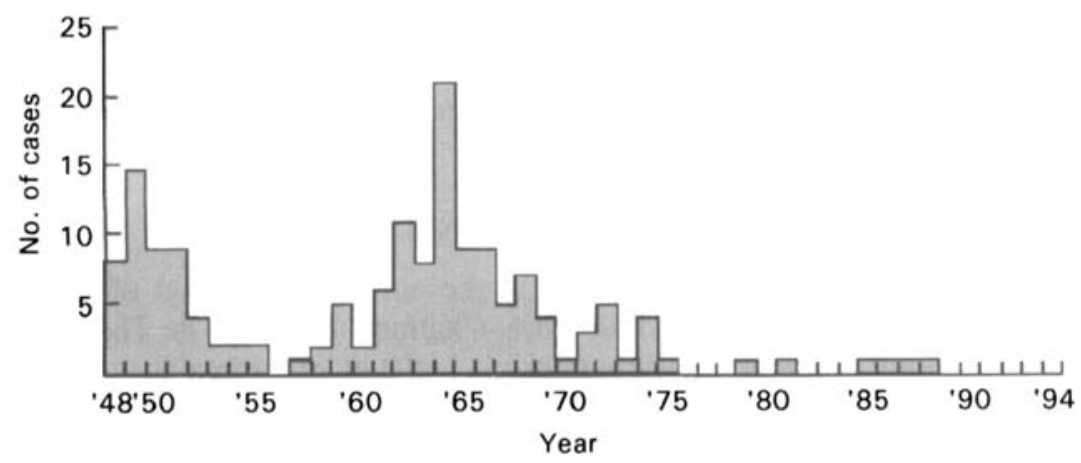

Fig. 3. Discharges of children with privational infantile rickets from the Royal Hospital for Sick Children, Glasgow between 1948 and 1967 and from all Glasgow hospitals between 1968 and 1994.

playing in traffic-free streets and parks in fine weather. He also observed that children who consumed a diet containing meat, suet, dripping and bacon fat rarely developed rickets. Cod liver oil was not routinely prescribed for infants and toddlers before Mellanby's (1920) discovery in 1919 of his anti-rachitic factor. Corry Mann's (1922) observations provide striking confirmation of the rachitogenic potential of a lacto-vegetarian diet in white infants and toddlers at levels of UVR exposure similar to those noted in Asian schoolchildren in Glasgow in the 1960s.

The increasing availability and affordability of proprietary infant foods containing meat, chicken, fish and eggs from the 1960s onward, and the current availability of food blenders ensures that most infants in the UK consume an omnivore diet from the age of about 4 months. Increasing affluence ensures that most toddlers consume a diet containing significant quantities of meat, eggs and fish in their second and third years of life. In a given population, there appears to be a direct correlation between meat intake and Fe status (Takkunen, 1976). Increased infant and toddler meat intakes and the shift from lactovegetarian to omnivore dietary patterns can be indirectly inferred from the decline in the prevalence of severe Fe-deficiency anaemia in infants and toddlers in the UK. The haem-Fe content of meat is more readily absorbed than vegetable-derived Fe, and meat consumption also promotes the absorption of vegetable-derived Fe. Arneil et al. (1965) found that $30 \%$ of Glasgow toddlers in poor areas of the city were severely anaemic (haemoglobin $<100 \mathrm{~g} / 1$ ) in the $1960 \mathrm{~s}$ in association with a high prevalence of infantile rickets. Grindulis et al. (1986) found a significant relationship between serum 25-hydroxycholecalciferol levels in Asian children in Birmingham and the presence of Fe-deficiency anaemia. Severe Fe-deficiency anaemia $(<100 \mathrm{~g} / 1)$ now affects only $1 \%$ of the toddler and preschool population (1.5-4.5 years) of the UK (Gregory et al. 1995).

In summary, the abolition of infantile rickets near the end of the 20th century from a city which had the highest incidence of this condition in the world at the beginning of the century (Hess, 1930) is mainly attributable to a gradual change in infant and toddler feeding patterns from lacto-vegetarian to omnivore. The introduction of vitamin D-fortified welfare foods and supplements during the Second World War played a significant but relatively minor role in this process. After the first year of life, Glasgow children do not consume vitamin D-fortified foods and only a small minority is provided with vitamin D supplements. There appears little justification for the current UK government policy of recommending the administration of vitamin D supplements to children up to 5 years of age who consume omnivore diets which provide complete protection from rickets. Rickets 
is occasionally seen in infants and toddlers from white and ethnic communities in the UK in association with late weaning and the consumption of foods high in carbohydrate (sugar, cereal and potato starch) without vitamin D supplements or fortified welfare foods.

\section{TRENDS IN THE PREVALENCE OF PRIVATIONAL OSTEOMALACIA IN THE UK}

Privational osteomalacia was first described in the elderly population of the UK in the 1960s (Gough et al. 1964; Anderson et al. 1966; Chalmers et al. 1967). The role of dietary factors in the aetiology of privational osteomalacia in the elderly remains unclear. No casecontrol studies measuring the daylight outdoor exposures and weighed dietary intakes of elderly patients with and without osteomalacia appear to have been carried out. Most geriatricians in Britain report a gradual decline in the prevalence of severe privational osteomalacia within the last 20 years. No systematic examination of the case records of hospital discharges with privational osteomalacia over this period has been carried out to confirm this impression. The decline in the prevalence of severe privational osteomalacia in the elderly may reflect improvements in the quality of the diets of most elderly patients associated with modest improvements in living standards and better social services.

\section{THE PREVALENCE OF PRIVATIONAL RICKETS AND OSTEOMALACIA IN SCOTLAND 1987-9}

The current prevalence of rickets and osteomalacia in Scotland was determined by examining the case records of patients discharged from all Scottish hospitals with these diagnoses during the 3 year period 1987-9. The case records of 355 of 416 discharges $(85 \%)$ were obtained. The causes of confirmed cases of rickets and osteomalacia are shown in Table 6. The ethnic origin, age and sex of patients with privational rickets or osteomalacia are shown in Table 7 , together with the probable presence of associated nutritional factors.

As in Glasgow, infantile rickets has been almost eliminated from Scotland near the end of the 20th century. The single case identified in the white population was the victim of ill-

Table 6. Diagnostic categories of 416 patients discharged from all Scottish hospitals with a diagnosis of rickets or osteomalacia 1987-9

(ICD 268; 1st-6th diagnosis)

\begin{tabular}{ll}
\hline \hline Diagnostic categories & $n$ \\
\hline Privational rickets or osteomalacia & 86 \\
Post-gastric surgery osteomalacia & 51 \\
Late effect rickets & 30 \\
Anticonvulsant rickets or osteomalacia & 28 \\
Renal rickets or osteomalacia & 25 \\
Coeliac rickets or osteomalacia & 15 \\
Hepatic osteomalacia & 10 \\
Rickets of prematurity & 8 \\
Hypophosphataemic rickets & 4 \\
Not confirmed & 98 \\
Unavailable records & 61 \\
& Total \\
\hline \hline
\end{tabular}

ICD, International Classification of Diseases. 
Table 7. Relationship of cases of privational rickets and osteomalacia discharged from all Scottish hospitals during 1987-9 to nutritional factors identified in the case record

\begin{tabular}{|c|c|c|c|c|c|}
\hline & \multirow[b]{2}{*}{ Total } & \multirow[b]{2}{*}{ Male } & \multirow[b]{2}{*}{ Female } & \multicolumn{2}{|c|}{$\begin{array}{c}\text { Nutritional factors } \\
\text { present* }\end{array}$} \\
\hline & & & & $\bar{n}$ & $\%$ of total \\
\hline \multicolumn{6}{|l|}{ Asian rickets and osteomalacia } \\
\hline Rickets & 3 & 1 & 2 & 3 & 100 \\
\hline Osteomalacia & 6 & 0 & 6 & 6 & 100 \\
\hline \multicolumn{6}{|l|}{ White rickets and osteomalacia } \\
\hline Infantile rickets & 1 & 1 & 0 & 1 & 100 \\
\hline Osteomalacia: $16-69$ years; & 6 & 2 & 4 & 5 & 83 \\
\hline $70-79$ years & 15 & 1 & 14 & 11 & 73 \\
\hline $80+$ years & 55 & 1 & 54 & 43 & 78 \\
\hline Total & 86 & 6 & 80 & 69 & 80 \\
\hline
\end{tabular}

* Recorded history of poor appetite, poor dietary intake, vegetarian dietary pattern, history and/or clinical evidence of weight loss.

treatment with accompanying malnutrition. The prevalence of Asian rickets and osteomalacia was also low, in keeping with the trend found in Glasgow.

Only six patients were discharged with a confirmed diagnosis of privational osteomalacia between 16 and 69 years. In all these patients, malnutrition associated with psychiatric illness and alcoholism could be identified. The great majority of discharges with evidence of biochemical, radiological or clinical osteomalacia without an identifiable cause were of patients in advanced old age (over 80 years). The clinical records suggested major nutritional problems in four in five patients. Where adequate documentation was available, the diets appeared to contain little or no meat, fish or eggs, consisting mainly of bread, biscuits, sandwiches, crisps and cakes. Milk was taken mainly in tea and consumption appeared low. Many patients were grossly underweight and hypoproteinaemic, with associated deficiencies of vitamin $\mathrm{C}$, folic acid and Fe. The great majority were handicapped by varying degrees of physical and mental incapacity with minimal UVR exposure.

The full results of this survey will be published in due course. The present summary indicates that nutritional factors associated with disorganized vegetarianism determine the prevalence and severity of privational osteomalacia in old age. Despite minimal UVR exposure, privational osteomalacia is rare in the large numbers of elderly people who consume an omnivore diet. As noted previously, hypovitaminosis D is common in the frail elderly British population and may contribute to the risk of type two osteoporosis by inducing secondary hyperparathyroidism. The dominant risk factor for hypovitaminosis D in elderly populations is deficient exposure to UVR; intestinal malabsorption and renal insufficiency may be contributing factors in some patients (Clements, 1992).

\section{CONCLUSION}

The UVR-diet model derived from the Glasgow Asian population indicates that the prevalence, severity and age distribution of privational rickets and osteomalacia are precisely delineated by the practice of varying degrees of vegetarianism or near-vegetarianism. Highfibre and -phytate diets are potentially rachitogenic in children, particularly at the pubertal 
growth spurt, but appear relatively innocuous in adults. Exposure to sufficient UVR neutralizes the rachitogenic or osteomalacic potential of the vegetarian diet in the presence of an adequate intake of dietary $\mathrm{Ca}$ (Fig. 1). The rarity of privational osteomalacia in white vegetarians in the UK appears related to their pursuit of a healthy lifestyle with high levels of outdoor exposure. Nevertheless, vegetarian diets may lead to privational rickets and osteomalacia, regardless of race, if exposure to UVR is sufficiently restricted (Chick $e t$ al. 1923; Dent \& Smith, 1969; Fogelman et al. 1979). There remains a need to explore the relationship between intakes of animal foods, particularly meat and meat products, and the intermediary metabolism of endogenously-synthesized vitamin D. Further unravelling of the nature of interactions between dietary factors and the vitamin D metabolic pathway remains the major unfinished task in understanding the aetiology of privational rickets and osteomalacia.

The studies noted in this review were made possible by grants from the Medical Research Council, the Scottish Home and Health Department and Greater Glasgow Health Board's Research Support Group. We are indebted to the members of the Glasgow Asian community whose willing participation and cooperation made these studies possible.

\section{REFERENCES}

Abdul Motaal, A., Gettinby, G., McIntosh, W. B., Sutherland, G. R. \& Dunnigan, M. G. (1985). Relationships between radiological and biochemical evidence of rickets in Asian schoolchildren. Postgraduate Medical Joumal 61, 307-312.

Alvarez, A. P., Anderson, K. E., Conney, A. H. \& Kappas, A. (1976). Interactions between nutritional factors and drug biotransformations in man. Proceedings of the National Academy of Sciences USA 73, 2501-2504.

Anderson, I., Campbell, A. E. R., Dunn, A. \& Runciman, J. B. M. (1966). Osteomalacia in elderly women. Scottish Medical Journal ii, 429-435.

Arnaud, S. B., Goldsmith, R. S., Lambert, P. N. \& Go, V. L. W. (1975). 25-hydroxyvitamin $\mathrm{D}_{3}$ : evidence of an enterohepatic circulation in man. Proceedings of the Society for Experimental Biology and Medicine 149, 570-572.

Arneil, G. C., McKilligin, H. R. \& Lobo, E. (1965). Malnutrition in Glasgow children. Scottish Medical Journal 10, $480-484$.

Brooke, O. G., Brown, I. R. F., Bone, C. D. M., Carter, N. D., Cleeve, H. J. W., Maxwell, J. D., Robinson, V. P. \& Winder, S. M. (1980). Vitamin D supplements in pregnant Asian women: effects on calcium status and fetal growth. British Medical Journal 1, 751-754.

Chalmers, J., Conacher, W. D. H., Gardner, D. L. \& Scott, P. R. (1967). Osteomalacia: a common disease in elderly women. Journal of Bone and Joint Surgery 49, 403-423.

Chan, W., Brown, J., Lee, S. M. \& Buss, D. H. (1995). Meat, Poultry and Game. Supplement to McCance and Widdowson's The Composition of Foods. London: Royal Society of Chemistry and Ministry of Agriculture, Fisheries and Food.

Chick, H., Dalyell, E. H., Hume, E. M., Mackay, H. M. M. \& Henderson Smith, H. (1923). Studies of Rickets in Vienna, 1919-1922: Report of the Accessory Food Factors Committee. Medical Research Council Special Report Series no. 77. London: H. M. Stationery Office.

Clements, M. R. (1989). The problem of rickets in U. K. Asians. Journal of Human Nutrition and Dietetics 2 , $105-116$

Clements, M. R. (1992). Vitamin D physiology and ageing. In Vitamin D. Proceedings of a Closed Workshop Held at the Royal Society of Medicine, pp. 7-16. Eastbourne: Practice Communications Limited.

Clements, M. R., Chalmers, T. M. \& Fraser, D. R. (1984). Enterohepatic circulation of vitamin D: a reappraisal of the hypothesis. Lancet i, 1376-1379.

Clements, M. R., Johnson, L. \& Fraser, D. R. (1987). A new mechanism for induced vitamin D deficiency in calcium deprivation. Nature 324, 62-65.

Compston, J. E. (1979). Rickets in Asian immigrants. British Medical Journal 2, 612

Corry Mann, H. (1922). Rickets. The Relative Importance of Environment and Diet as Factors of Causation: an Investigation in London. Medical Research Council Special Report Series no. 68. London: H. M. Stationery Office. 
Dandona, P., Okonofua, F. \& Clements, R. V. (1985). Osteomalacia during pregnancy presenting as pathological fractures during pregnancy in Asian women of high socioeconomic status. British Medical Journal 290, 837838.

Dent, C. E. (1974). Definition of osteomalacia. Lancet i, 805.

Dent, C. E. \& Gupta, M. M. (1975). Plasma 25-hydroxyvitamin D levels during pregnancy in Caucasians and in vegetarian and non-vegetarian Asians. Lancet ii, 1057-1060.

Dent, C. E. \& Smith, R. (1969). Nutritional ostcomalacia. Quarterly Journal of Medicine 38, 195-209.

Dollery, C. T., Fraser, H. S., Davies, D. \& MacIntyre, I. (1977). Vitamin D status in different subgroups of British Asians. Lancet i, 104.

Dunnigan, M. G. (1977). Asian rickets and osteomalacia in Britain. In Child Nutrition and its Relation to Mental and Physical Development, pp. 43-70. Manchester: Kellogg Company of Great Britain.

Dunnigan, M. G. (1992). Vitamin D status in Asian subjects. In Vitamin D. Proceedings of a Closed Workshop Held at the Royal Society of Medicine, pp. 16-20. Eastbourne: Practice Communications Limited.

Dunnigan, M. G., Childs, W. C., Smith, C. M., McIntosh, W. B. \& Ford, J. A. (1975). The relative roles of ultraviolet deprivation and diet in the aetiology of Asian rickets. Scottish Medical Journal 20, 217-218.

Dunnigan, M. G., Glekin, B. M., Henderson, J. B., McIntosh, W. B., Sumner, D. \& Sutherland, G. R. (1985). Prevention of rickets in Asian children: assessment of the Glasgow campaign. British Medical Journal 291 239-242.

Dunnigan, M. G., Mclntosh, W. B. \& Ford, J. A. (1976). Rickets in Asian immigrants. Lancet i, 1346.

Dunnigan, M. G., McIntosh, W. B., Ford, J. A. \& Robertson, I. (1982). Acquired disorders of vitamin D metabolism. In Calcium Disorders: Clinical Endocrinology, vol. 11, pp. 125-150 [D. Heath and S. J. Marx, editors]. London: Butterworths.

Dunnigan, M. G., Paton, J. P. J., Haase, S., McNicol, G. W., Gardner, M. D. \& Smith, C. M. (1962). Late rickets and osteomalacia in the Pakistani community in Glasgow. Scottish Medical Journal 7, 159-167.

Dunnigan, M. G. \& Smith, C. M. (1965). The aetiology of late rickets in Pakistani children in Glasgow, Report of a diet survey. Scottish Medical Journal 10, 1-9.

Fogelman, I., Boyce, B. \& Boyle, I. T. (1979). Rickets in a white adolescent. Postgraduate Medical Journal 55, 808-809.

Ford, J. A., Colhoun, E. M., McIntosh, W. B. \& Dunnigan, M. G. (1972a). Rickets and osteomalacia in the Glasgow Pakistani community, 1961-1971. British Medical Journal 2, 677-680.

Ford, J. A., Colhoun, E. M., McIntosh, W. B. \& Dunnigan, M. G. (1972b). Biochemical response of late rickets and osteomalacia to a chapatti-free diet. British Medical Journal 3, 446-447.

Ford, J. A., Davidson, D. C., McIntosh, W. B., Fyfe, W. M. \& Dunnigan, M. G. (1973). Neonatal rickets in Asian immigrant population. British Medical Journal 3, 211 1-212.

Fraser, D. R. (1995). Fat-soluble vitamins. Vitamin D. Lancet 345, 104-108.

Gough, K. R., Lloyd, O. C. \& Wills, M. R. (1964). Nutritional osteomalacia. Lancet ii, 1261-1264.

Gregory, J. R., Collins, D. L., Davies, P. S. W., Hughes, J. M. \& Clarke, P. C. (1995). National Diet and Nutrition Survey: Children Aged 1/2 to 41/2 years. Vol. 1, Report of the Diet and Nutrition Survey. London: H. M. Stationery Office.

Grindulis, H., Scott, P. H., Belton, N. R. \& Wharton, B. A. (1986). Combined deficiency of iron and vitamin D in Asian toddlers. Archives of Disease in Childhood 61, 843-848.

Gupta, M. M., Round, J. M. \& Stamp, T. C. B. (1974). Spontaneous cure of vitamin-D deficiency in Asians during summer in Britain. Lancet $\mathrm{i}$, 586-588.

Henderson, J. B., Dunnigan, M. G., McIntosh, W. B., Abdul Motaal, A., Gettinby, G. \& Glekin, B. M. (1987). The importance of limited exposure to ultra-violet radiation and dietary factors in the aetiology of Asian rickets: a risk-factor model. Quarterly Journal of Medicine 63, 413-425.

Henderson, J. B., Dunnigan, M. G., McIntosh, W. B., Abdul Motaal, A. \& Hole, D. (1990). Asian osteomalacia is determined by dietary factors when exposure to ultraviolet radiation is restricted: a risk factor model. Quarterly Journal of Medicine 76, 923-933.

Henderson, J. B., Glekin, B. M., McIntosh, W. B. \& Dunnigan, M. G. (1989). A health education campaign to prevent osteomalacia in Asian women in Glasgow: 1984-86. Joumal of Human Nutrition and Dietetics 2, 237-251.

Hess, A. F. (1930). Rickets Including Osteomalacia and Tetany. London: Henry Kimpton.

Holmes, A. M., Enoch, B. A., Taylor, J. L. \& Jones, M. E. (1973). Occult rickets and osteomalacia amongst the Asian immigrant population. Quarterly Journal of Medicine 42, 125-149.

Hunt, S. P., O'Riordan, J. L. H., Windo, J. \& Truswell, A. S. (1976). Vitamin D status in different subgroups of British Asians. British Medical Journal 2, 1351-1354.

James, W. P. T., Branch, W. J. \& Southgate, D. A. T. (1978). Calcium binding by dietary fibre. Lancet i, 638639.

Jessop, W. J. E. (1950). Results of rickets surveys in Dublin. British Journal of Nutrition 4, 289-295.

Matheson, L. M., Henderson, J. B., Hole, D. \& Dunnigan, M. G. (1988). Changes in the incidence of acute appendicitis in Glasgow Asian and white children between 1971 and 1985. Journal of Epidemiology and Community Health 42, 290-293. 
Mellanby, E. (1920). Accessory food factors (vitamins) in the feeding of infants. Lancet i, 856-862.

Mellanby, E. (1921). Experimental Rickets. Medical Research Council Special Report Series no. 61, London: H. M. Stationery Office.

Mellanby, E. (1949). Rickets-producing and anti-calcifying action of phytate. Journal of Physiology 109, 488533.

Okonofua, F., Gill, D. S., Alabi, Z. O., Thomas, M., Bell, J. L. \& Dandona, P. (1991). Rickets in Nigerian children: a consequence of calcium malnutrition. Metabolism 40, 209-213.

Pettifor, J. M., Ross, F. P., Wang, J., Moodley, G. \& Couper-Smith, J. (1978). Rickets in children of rural origin in South Africa: is low dietary calcium a factor? Journal of Pediatrics 92, 320-324.

Pietrek, J., Windo, J., Preece, M. A., O'Riordan, J. L. H., Dunnigan, M. G., McIntosh, W. B. \& Ford, J. A. (1976). Prevention of vitamin D deficiency in Asians. Lancet i, 1145-1148.

Poskitt, E. M. E., Cole, T. J. \& Lawson, D. E. M. (1979). Diet, sunlight and 25-hydroxyvitamin D in healthy children and adults. British Medical Journal 1, 221-223.

Preece, M. A., Tomlinson, S., Ribot, C. A., Pietrek, J., Korn, H. T., Davies, D. M., Ford, J. A., Dunnigan, M. G. \& O'Riordan, J. L. H. (1975). Studies of vitamin D deficiency in man. Quarterly Journal of Medicine 44, 575589.

Reeve, L. E., Jorgensen, R. A. \& De Luca, H. F. (1982). Vitamin D compounds in cows' milk. Journal of Nutrition 112, 667-672,

Rheinhold, J. G. (1972). Nutritional osteomalacia in immigrants in an urban community. Lancet i, 386.

Rheinhold, J. G. (1976). Rickets in Asian immigrants. Lancet ii, 1132.

Richards, I. D. G., Sweet, E. M. \& Arneil, G. C. (1968). Infantile rickets persists in Glasgow. Lancet i, $803-805$.

Robertson, I., Ford, J. A., McIntosh, W. B. \& Dunnigan, M. G. (1981). The role of cereals in the aetiology of nutritional rickets: the lesson of the Irish National Nutritional Survey 1943-8. British Journal of Nutrition 45, 17-32.

Robertson, I., Glekin, B. M., Henderson, J. B., McIntosh, W. B., Lakhani, A. \& Dunnigan, M. G. (1982). Nutritional deficiencies among ethnic minorities in the United Kingdom. Proceedings of the Nutrition Society 41, 243-256.

Shah, B. G. (1981). Bioavailability of trace elements in human nutrition. Progress in Clinical and Biological Research 77, 199-208.

Snedeker, S. M. \& Greger, J. L. (1983). Metabolism of zinc, copper, and iron as affected by dietary protein, cysteine and histidine. Joumal of Nutrition 113, 644-652.

Stamp, T. C. B., Waiker, P. G., Perry, W. \& Jenkins, M. V. (1980). Nutritional osteomalacia and late rickets in Greater London 1974-79: clinical and metabolic studies in 45 patients. Clinics in Endocrinology and Metabolism 9, 81-105.

Takkunen, H. (1976). Iron status in the Finnish adult population. Scandinavian Journal of Haematology 25, Suppl., 1-91.

Wills, M. R., Day, R. C., Phillips, J. B. \& Bateman, E. C. (1972). Phytic acid and nutritional rickets in immigrants. Lancet i, 771-773. 